\title{
Weight Loss Is Associated With Increased Serum 25- Hydroxyvitamin D in Overweight or Obese Women
}

\author{
Cheryl L. Rock ${ }^{1}$, Jennifer A. Emond ${ }^{1}$, Shirley W. Flatt ${ }^{1}$, Dennis D. Heath ${ }^{1}$, Njeri Karanja ${ }^{2}$, \\ Bilge Pakiz ${ }^{1}$, Nancy E. Sherwood ${ }^{3}$, and Cynthia A. Thomson ${ }^{4}$ \\ ${ }^{1}$ Department of Family and Preventive Medicine, and Moores UCSD Cancer Center, University of \\ California, San Diego, La Jolla, California, USA \\ ${ }^{2}$ Kaiser Permanente Center for Health Research, Portland, Oregon, USA \\ ${ }^{3}$ Health Partners Research Foundation, and Division of Epidemiology and Community Health, \\ School of Public Health, University of Minnesota, Minneapolis, Minnesota, USA \\ ${ }^{4}$ Department of Nutritional Sciences and the Arizona Cancer Center, University of Arizona, \\ Tucson, Arizona, USA
}

\begin{abstract}
Low circulating concentrations of vitamin D metabolites have been associated with increased risk for several diseases and clinical conditions. Large observational studies and surveys have shown that obesity is independently associated with lower serum 25-hydroxyvitamin $\mathrm{D}(25(\mathrm{OH}) \mathrm{D})$ concentration. Few studies have examined the effect of weight loss on serum $25(\mathrm{OH}) \mathrm{D}$ concentration. The purpose of this study was to prospectively examine the effect of weight loss on serum 25(OH)D concentration. Data were collected from 383 overweight or obese women who participated in a 2-year clinical trial of a weight-loss program, in which $51 \%(N=195)$ lost at least $5 \%$ of baseline weight by 24 months, $18 \%(N=67)$ lost $5-10 \%$, and $33 \%(N=128)$ lost $>10 \%$. Women who did not lose weight at 24 months had an increase in serum 25(OH)D of $1.9(9.7) \mathrm{ng} /$ $\mathrm{ml}($ mean $(\mathrm{SD})) ; 25(\mathrm{OH}) \mathrm{D}$ increased by $2.7(9.1) \mathrm{ng} / \mathrm{ml}$ for those who lost $5-10 \%$ of baseline weight; and 25(OH)D increased by $5.0(9.2) \mathrm{ng} / \mathrm{ml}$ for those who lost $>10 \%$ of baseline weight $(P$ $=0.014)$. At baseline, 51\% $(N=197)$ of participants met or exceeded the recommended serum concentration of $20 \mathrm{ng} / \mathrm{ml}$. By study end, 64\% $(N=230)$ of overweight or obese women met this goal, as well as $83 \%(N=20)$ of those whose weight loss achieved a normal BMI. These findings suggest that weight loss, presumably associated with a reduction in body fat, is associated with increased serum 25(OH)D concentration in overweight or obese women.
\end{abstract}

\section{INTRODUCTION}

Vitamin D is essential for good health. Poor vitamin D status or low circulating concentrations of vitamin D metabolites have been associated with increased risk for numerous diseases, including osteoporosis, several types of cancer, diabetes, hypertension, and cardiovascular disease (1-3), although not consistently (4). Serum 25-hydroxyvitamin D $(25(\mathrm{OH}) \mathrm{D})$ concentration is believed to be the single best assessment of vitamin D status.

\footnotetext{
C 2012 The Obesity Society

Correspondence: Cheryl L. Rock (clrock@ucsd.edu).

DISCLOSURE

The authors declared no conflict of interest.

See the online ICMJE Conflict of Interest Forms for this article.
} 
Numerous large observational studies and surveys have shown that obesity is associated with lower serum 25(OH)D concentration in multivariate analysis that considers dietary intake, sun exposure, and other potentially influencing factors (5-9). Lower levels of serum $25(\mathrm{OH}) \mathrm{D}$ in association with excess adiposity has been suggested to be due to sequestration in fat $(6,10,11)$ although confounding by less sun exposure in obese individuals is another possible explanation (12). Of interest, the trends seen in vitamin $\mathrm{D}$ inadequacy based on serum 25(OH)D levels in the United States have paralleled the rates of overweight and obesity (6).

Change in serum 25(OH)D concentration associated with weight loss induced by gastric or intestinal bypass surgeries for the treatment of obesity has been examined in several previous studies. However, the effect of weight loss promoted by these surgeries is confounded by surgery-induced malabsorption and the routine use of vitamin D-containing dietary supplements following these bariatric surgeries $(13,14)$. In contrast, there is a paucity of evidence relating to the effect of a reduction in body fat mass achieved with behavioral strategies to promote weight loss on changes in serum $25(\mathrm{OH}) \mathrm{D}$ concentration.

The primary aim of this study was to investigate the relationship between weight loss and change in serum $25(\mathrm{OH}) \mathrm{D}$ concentration in overweight or obese women who participated in a clinical trial of a weight-loss program. Data are from a randomized trial that enrolled overweight or obese women and followed them over a 2-year period of time (15). With serum samples collected at the baseline and 12- and 24-month time points, the longitudinal relationship between weight loss and serum $25(\mathrm{OH}) \mathrm{D}$ concentration can be examined. Demonstrating a favorable effect of weight loss resulting from behavioral counseling to promote a healthier diet and increased physical activity on serum $25(\mathrm{OH}) \mathrm{D}$, a marker of vitamin D status, informs the assessment of disease risk and clinical recommendations for women who are overweight or obese.

\section{METHODS AND PROCEDURES}

\section{Subjects and study design}

Data for this study are from a 2-year randomized clinical trial of a weight-loss program that targeted overweight or obese women (BMI 25-40 weight $(\mathrm{kg}) /$ height $\left(\mathrm{m}^{2}\right)$ ) between November 2007 and April 2010 (15). Women were recruited from four sites in the United States: University of California, San Diego; Kaiser Portland Center for Health Research; University of Arizona; and University of Minnesota. Eligibility criteria included the following: aged $\geq 18$ years; BMI $25-40 \mathrm{~kg} / \mathrm{m}^{2}$ and a minimum of $15 \mathrm{~kg}$ over ideal weight as defined by actuarial tables; not pregnant or breastfeeding or planning to become pregnant in the next 2 years; willing to participate in any of the three study groups over a 2-year period; no eating disorders, food allergies or intolerances; and willing and able to perform a simple step test for assessing cardiopulmonary fitness. Current active involvement in another diet intervention study or organized weight-loss program, or having a history or presence of a significant psychiatric disorder or any other condition that, in the investigator's judgment, would interfere with participation in the trial, also disqualified women.

Overall, 442 women (77\% non-Hispanic white), with mean (SD) BMI of 33.7 (3.4) kg/m², were enrolled in the trial and were randomized to one of three study groups. Participants were randomly assigned in a 3:3:2 allocation to the in-person program intervention, the telephone-based program intervention, or the usual care group, stratified for BMI, age, and clinic site. Randomization was computerized using a web-based data application run at each clinical site by research staff, using a sequence generated by the study statistician. Analyses were limited to the 383 women for whom 24-month weight and serum 25(OH)D data were available. 
Women assigned to two of the study groups participated in a comprehensive multifaceted weight-loss program, which included an energy-reduced diet prescription, recommendations to increase physical activity to at least 30 min of moderate activity at least 5 days a week, and behavioral counseling either in person or by telephone. The diet component of the program consisted of a nutritionally adequate, reduced-fat (20-30\% of energy), reducedenergy (typically 1,200-2,000 kcal/day) diet that included prepackaged prepared food items that incorporated and were accompanied by increased vegetables and fruits to reduce the energy density of the diet. The approach was tailored, so that participants could choose regular foods when preferred. Women assigned to the remaining arm served as a usual care comparison group, in which women were provided general weight-loss counseling with a dietetics professional at baseline and 6 months.

\section{Measurements}

Women completed clinic visits at baseline and every 6 months, at which weight and height were measured and BMI was calculated. The 3-min step test was used to assess cardiopulmonary fitness, categorized as "good to excellent" or "poor to fair" based on age (16), at these clinic visits. This test measures heart rate during the first $30 \mathrm{~s}$ of recovery from stepping, and although less accurate than measuring maximal oxygen uptake $\left(\mathrm{VO}_{2} \max \right)$, the test has high reliability, is sensitive to change, and correlates with level of physical activity in intervention programs (17).

Participants were asked to bring to the clinic visit any dietary supplements they were using, including multivitamins, at follow-up clinic visits; baseline supplement use was imputed based on duration of use reported on a 12-month questionnaire. Brand names and amounts of vitamin D (IU/day) from supplements were recorded and categorized as 0, 1-400, 401999, and $\geq 1,000 \mathrm{IU} /$ day. An intake of $400 \mathrm{IU} /$ day would meet the recommended adequate intake level of $10 \mu \mathrm{g} /$ day for women aged $>50$ years applicable at the time of data collection.

Blood samples also were collected at these clinic visits. The present study focused on the baseline and 12- and 24-month samples to minimize the effect of seasonal variations in serum 25(OH)D related to UV light exposure. The baseline and 12- and 24-month clinic visits at which blood samples were collected for this study were scheduled from November to January.

\section{Analytic methods}

For this study, we used a chemiluminescent immunoassay method to measure the combined $25(\mathrm{OH}) \mathrm{D}_{2}$ and $25(\mathrm{OH}) \mathrm{D}_{3}$ isoforms. The results were reported as total serum $25(\mathrm{OH}) \mathrm{D}$. Also, a high-performance liquid chromatography (HPLC) method was used to separate and quantify $25(\mathrm{OH}) \mathrm{D}_{2}$ and $25(\mathrm{OH}) \mathrm{D}_{3}$.

Total serum 25(OH)D concentration was measured using the Dia-Sorin LIAISON chemiluminescent procedure by a commercial laboratory (Arup Laboratories, Salt Lake City UT). The assay range is $7.0-150 \mathrm{ng} / \mathrm{ml}$ and the lowest reportable value is $7.0 \mathrm{ng} / \mathrm{ml}$.

We used HPLC equipment from Varian (Walnut Creek, CA), a model 410 auto sampler, 325 UV/VIS dual wavelength detector, and Prostar 230 reagent pump and the ClinRep Complete $25(\mathrm{OH})$ Vitamin $\mathrm{D}_{2} / \mathrm{D}_{3}$ Kit (Iris Technologies, Olathe, KS). Recovery is $99-104 \%$ and assay linearity is between $3.0-500 \mathrm{ng} / \mathrm{ml}$ for $25(\mathrm{OH}) \mathrm{D}_{2}$ and $2.6-500 \mathrm{ng} / \mathrm{ml}$ for $25(\mathrm{OH}) \mathrm{D}_{3}$. The lower limit of detection is 1.1 and $2.6 \mathrm{ng} / \mathrm{ml}$, respectively.

To monitor the HPLC method performance, the laboratory participates in the international Vitamin D External Quality Assessment Scheme (DEQAS) proficiency survey (18), and more recently, the newly inaugurated National Institute of Standards and Technology 
(NIST) vitamin D quality assurance exercise. We routinely used one in-house serum pool and four additional purchased quality control samples covering the analytical range from $6.0-150 \mathrm{ng} / \mathrm{ml}$. The batched sample results were accepted only if these internal quality control results were within 2 SDs of the assigned values.

\section{Statistical methods}

Weight loss at 24 months was computed as absolute loss $(\mathrm{kg})$ and as percent change from baseline weight (\%). Weight loss at 24 months was categorized as no weight loss (i.e., gain or stable within 5\% of baseline weight), a 5-10\% weight loss, and a weight loss of more than $10 \%$. Baseline participant characteristics were summarized by categories of weight loss, and significant differences were assessed using $\chi^{2}$ tests of comparisons. Baseline serum $25(\mathrm{OH}) \mathrm{D}$ concentrations were also compared across participant characteristics, with mean differences compared using $t$-tests or ANOVA methods as appropriate. Concentrations of serum $25(\mathrm{OH}) \mathrm{D}$ were reported as means and $\mathrm{SD}$ to be consistent with reporting from the third National Health and Nutrition Examination Survey (19). Simple linear regression was used to test a linear relationship between the mean concentration of $25(\mathrm{OH}) \mathrm{D}$ over these ordered categories.

Linear regression was used to model the 24-month change in serum $25(\mathrm{OH}) \mathrm{D}$ concentrations on 24-month weight loss, adjusted for baseline concentration of $25(\mathrm{OH}) \mathrm{D}$, study group, clinic site, baseline age, race/ethnicity, baseline BMI (25-29.9 vs. $\left.230 \mathrm{~kg} / \mathrm{m}^{2}\right)$, vitamin D supplement use at 24 months, and fitness level at 24 months. These measures were selected a priori based on stratification variables used for randomization (BMI, age, clinic site) and based on measures found to be related to 25(OH)D concentrations at baseline (race/ethnicity, fitness level, and supplement use). Analyses were completed using the R language for statistical computing, version 2.11.0 and SAS version 9.2 (SAS Institute, Cary, $\mathrm{NC})$.

\section{RESULTS}

By 24 months, $51 \%$ of the women enrolled in the study $(N=195)$ lost at least $5 \%$ of their baseline weight (Table 1); 18\% $(N=67)$ lost $5-10 \%$; and 33\% $(N=128)$ lost $>10 \%$. Of the women who did not achieve a weight loss of at least $5 \%$ by month 24,160 women $(42 \%$ of the overall sample were within 5\% of their baseline weight, $5 \%(n=20)$ had gained 5-10\%, and $2 \%(n=8)$ had gained more than $10 \%$ of their baseline weight. Average weight change for this group was a gain of $0.7(4.5) \mathrm{kg}$ (mean (SD)) by 24 months. Among those who did lose at least $5 \%$ of their baseline weight, average weight loss was $6.9(1.5) \mathrm{kg}$ for those who lost between 5-10\% of their baseline weight and $16(5.8) \mathrm{kg}$ for those who lost $>10 \%$.

In bivariate analysis, baseline serum 25(OH)D concentration was significantly related to clinical site and the following participant characteristics: race/ethnicity, BMI, and supplement use (Table 2). Comparison of results from the two laboratory methods showed that the $25(\mathrm{OH}) \mathrm{D}_{3}$ isoform (measured using the HPLC methodology) accounted for $90 \%$ of the total $25(\mathrm{OH}) \mathrm{D}$ measured using the chemiluminescent methodology, and these measures were highly correlated $(r=0.94, P<0.001)$.

Vitamin D supplement use increased for all women over the course of the trial. Twenty percent of women reported that they were taking some form of a vitamin D supplement at baseline, which increased to $48 \%$ at 12 months and to $50 \%$ at 24 months $(P<0.001)$. Further, by 24 months, $19 \%$ of women $(N=72)$ were taking supplement doses between $1-$ $400 \mathrm{IU} /$ day, $15 \%(N=56)$ took doses between $400-999 \mathrm{IU} /$ day, and $16 \%(N=62)$ took $\geq 1,000$ IU/day. Importantly, supplement use did not differ across the 24-month weight loss categories at any time point (data not shown). 
Changes in serum $25(\mathrm{OH}) \mathrm{D}$ concentration were mildly, inversely correlated with changes in weight by 24 months when both variables were treated as continuous measures $(r=-0.16, P$ $=0.001)$. When categorized, women who gained weight decreased their serum $25(\mathrm{OH}) \mathrm{D}$ by $0.6(7.5) \mathrm{ng} / \mathrm{ml}$; those with stable weight had an average increase in serum $25(\mathrm{OH}) \mathrm{D}$ of 2.3 (10.0) $\mathrm{ng} / \mathrm{ml}$; for those who lost 5-10\% of their baseline weight, serum 25(OH)D increased by $2.7(9.1) \mathrm{ng} / \mathrm{ml}$; and for those who lost $>10 \%$ of their baseline weight, serum $25(\mathrm{OH}) \mathrm{D}$ increased by $5.0(9.2) \mathrm{ng} / \mathrm{ml}(P=0.014)$. Figure 1 displays mean change in serum $25(\mathrm{OH}) \mathrm{D}$ at 24 months by categories of 24 -month weight change. Although limited by sample size, a significant, linear trend is seen in the change of serum $25(\mathrm{OH}) \mathrm{D}$ concentration by 24 -month weight change categories when further refined $(P=0.005)$. Of note, $52 \%$ of participants, all of whom were overweight or obese, $(N=197)$ met or exceeded the recommended serum concentration of $20 \mathrm{ng} / \mathrm{mL}$ at baseline $(4,20)$. By study end, $64 \%$ of overweight or obese women $(N=230)$ met this goal, as well as $83 \%(N=20)$ of those whose weight loss enabled them to achieve a normal BMI.

Table 3 presents the fully adjusted regression model for change in serum 25(OH)D concentration on 24-month weight-loss categories. Weight loss greater than $10 \%$ of baseline weight remained significantly related to increased $25(\mathrm{OH}) \mathrm{D}$ concentration by 24 months, with women who experienced this level of weight loss experiencing an increase of $2.6 \mathrm{ng} / \mathrm{ml}$ in serum $25(\mathrm{OH}) \mathrm{D}$ concentration compared to women who did not lose weight.

\section{DISCUSSION}

Findings from this study suggest that weight loss, with an expected reduction in body fat mass, is associated with increased serum $25(\mathrm{OH}) \mathrm{D}$ concentration in overweight or obese women in a dose-response manner, independent of changes in fitness level or vitamin D supplement use. During the course of this study, a substantial number of these women achieved a clinically significant weight loss (33\% of the sample lost $>10 \%$ of initial body weight), although this degree of weight loss did not normalize BMI for most of them during the 2-year time period. The effect of weight loss on serum 25(OH)D in the overall group was relatively modest during the time frame under study but was clearly greater for women who lost the most weight. Few previous studies have demonstrated or reported the effect of weight loss on $25(\mathrm{OH}) \mathrm{D}$ resulting from a behavioral weight-loss program promoting an energy deficit in overweight or obese individuals. In a study which was primarily focused on the effect of diet-induced weight loss with or without calcium supplementation on bone mass in 62 overweight or obese women (BMI $25.2-51.6 \mathrm{~kg} / \mathrm{m}^{2}$ ), an average weight loss of $5.2 \mathrm{~kg}$ (5.6\% of initial weight) was not associated with significant changes in serum 25(OH)D after a 3-month intervention (21). In 35 overweight or obese children in whom BMI was reduced from 27.3 (3.5) to $26.4(3.0) \mathrm{kg} / \mathrm{m}^{2}$ (mean (SD)) during a 1-year obesity intervention program, serum 25(OH)D increased from 11 (4) to 16 (9) $\mathrm{ng} / \mathrm{ml}(9)$. In a comparison of two energy-reduced diets, one emphasizing vegetables and the other including vitamin D-fortified cereals, effects on serum 25(OH)D were examined in 61 overweight or obese women (BMI $28.1(3.1) \mathrm{kg} / \mathrm{m}^{2}$ ) (22). After 2 weeks on these diets, women eating the cereal diet lost more weight and demonstrated a significant increase in serum 25(OH)D, from $24.0(16.8)$ to $27.0(16.3) \mathrm{ng} / \mathrm{ml}$, but the concurrent increase in vitamin $\mathrm{D}$ intake and the very brief time frame constrains interpretation of these findings. In another small study, 25(OH)D was observed to increase from $15.4(6.0)$ to $18.3(5.1) \mathrm{ng} / \mathrm{ml}$ in 26 obese women (BMI $36.7(4.9) \mathrm{kg} / \mathrm{m}^{2}$ ) in response to a $10 \%$ weight loss following 20 weeks of an energy-restricted diet (23).

Reports of the effects of weight loss induced by gastric and intestinal bypass surgery on serum 25(OH)D concentration are mixed (14,24-26). Also, the effect of weight loss resulting from bariatric surgery on serum $25(\mathrm{OH}) \mathrm{D}$ is confounded by the malabsorption that 
often results from these procedures and the standard practice of prescribing supplemental micronutrients, including vitamin $\mathrm{D}$, as a component of post-surgery patient care $(13,14)$.

The $25(\mathrm{OH}) \mathrm{D}_{3}$ form of $25(\mathrm{OH}) \mathrm{D}$ was the major form of the total $25(\mathrm{OH}) \mathrm{D}$ in the circulation of the study participants, indicating that the majority of $25(\mathrm{OH}) \mathrm{D}$ was obtained from endogenous synthesis or cholecalciferol consumed as a food fortificant or dietary supplement. Our results are similar to those reported by Roth et al. (27) and others, in which the majority of $25(\mathrm{OH}) \mathrm{D}$ in the circulation is in the form of $25(\mathrm{OH}) \mathrm{D}_{3}$.

Adipose tissue is known to be the primary site of vitamin D accumulation (4). The proposed mechanism to explain the findings in this study is that a reduction in fat mass reduces the pool in which vitamin D can be sequestered. Wortman et al. (10) compared the response of obese $\left(n=19\right.$, BMI $\left.230 \mathrm{~kg} / \mathrm{m}^{2}\right)$ and matched lean control $\left(n=19\right.$, BMI $\left.\_5 \mathrm{~kg} / \mathrm{m}^{2}\right)$ subjects to UVB irradiation and an oral dose (50,000 IU) of vitamin $\mathrm{D}_{2}$. The obese group showed an attenuated response in vitamin $\mathrm{D}_{3}$ concentration following UVB irradiation, and the kinetics of the $25(\mathrm{OH}) \mathrm{D}$ response to the oral dose was significantly different in the two groups, with a significant time-by-group interaction. Peak serum vitamin $\mathrm{D}_{2}$ after oral intake was significantly correlated with BMI $(r=-0.56, P=0.007)$, and the obese group showed minimal change in total serum $25(\mathrm{OH}) \mathrm{D}$ in response to the oral dose. These responses suggest that more vitamin D was sequestered in the obese, with a larger pool of body fat, following either endogenous synthesis or oral ingestion. A recent study that was focused on comparing the potency of vitamin $\mathrm{D}_{2}$ and $\mathrm{D}_{3}$, rather than differential response in obese vs. nonobese individuals, confirms the uptake of vitamin $\mathrm{D}$ by adipose tissue following administration (28). In that study, 33 subjects with a mean BMI of $25.5 \mathrm{~kg} / \mathrm{m}^{2}$ were administered a weekly oral dose of $50,000 \mathrm{IU}$ vitamin $\mathrm{D}_{2}$ or $\mathrm{D}_{3}$ for 12 weeks, and in nine of these subjects, vitamin D content of adipose tissue was measured at baseline and following the 12-week treatment. Adipose tissue vitamin D increased by an average of $57 \mu \mathrm{g} / \mathrm{kg}$ in those treated with vitamin $\mathrm{D}_{2}$ and by $104 \mu \mathrm{g} / \mathrm{kg}$ in those treated with vitamin $\mathrm{D}_{3}(28)$.

Other explanations for the lower serum 25(OH)D observed in obese individuals include associated lifestyle and behavioral factors, such as lower levels of physical activity, perhaps confounded by less sun exposure $(11,12)$. However, the inverse association between obesity and serum 25(OH)D remains when adjusted for physical activity and/or sun exposure in observational studies $(6,29)$.

This study has some limitations. Sun exposure, which is an important determinant of serum $25(\mathrm{OH}) \mathrm{D}$ concentration, was not measured. Physical activity and body fat also were not measured. It is possible that weight loss was associated with increased outdoor physical activity and UVB exposure resulting in enhanced endogenous synthesis of vitamin D. However, the reference season (November to January) when samples were collected and the analysis is focused is one in which UV radiation exposure from sunlight is low. Another possible limitation is that dietary intake, including vitamin D intake from food sources, was not measured. The fact that there are few naturally good food sources of vitamin D and that overall intake of food was decreased during weight loss make confounding by diet less likely.

In summary, low serum 25(OH)D concentration in overweight or obese individuals can be favorably modified by a behavioral weight loss intervention. Weight loss and maintenance of that loss in overweight or obese women improves vitamin D status in addition to having favorable effects on established cardiovascular disease risk factors $(15,30)$. 


\section{Acknowledgments}

This study was funded by Jenny Craig, Inc., Carlsbad, CA. J.A.E. is a recipient of a Ruth L. Kirschstein National Research Service Award (NRSA) Institutional Training Grant (T32), awarded to San Diego State University by the National Institute of General Medical Sciences (T32 GM084896). The study is registered in http://

clinicaltrials.gov/, registration number NCT00640900. C.L.R. had full access to all the data in the study and takes responsibility for the integrity of the data and the accuracy of the data analysis. The sponsor, Jenny Craig, Inc., had a minimal role in the design and protocol development. By contractual agreement, scientists at the University of California, San Diego, and the other participating institutions had responsibility and independence regarding data management, analysis, and publication. The funding sponsor had no role in the collection, analysis, or interpretation of the data; or in the preparation, review or approval of the manuscript.

\section{REFERENCES}

1. Holick MF. Sunlight and vitamin D for bone health and prevention of autoimmune diseases, cancers, and cardiovascular disease. Am J Clin Nutr. 2004; 80:1678S-1688S. [PubMed: 15585788]

2. Holick MF, Chen TC. Vitamin D deficiency: a worldwide problem with health consequences. Am J Clin Nutr. 2008; 87:1080S-1086S. [PubMed: 18400738]

3. Vieth, R. The pharmacology of vitamin D, including fortification strategies. In: Feldman, D.; Glorieux, F.; Pike, JW., editors. Vitamin D. New York, NY: Elsevier; 2005. p. 995-1015.

4. Dietary Reference Intakes for Calcium and Vitamin D. Washington, DC: The National Academies Press; 2011. IOM (Institute of Medicine).

5. Valiña-Tóth AL, Lai Z, Yoo W, et al. Relationship of vitamin D and parathyroid hormone with obesity and body composition in African Americans. Clin Endocrinol (Oxf). 2010; 72:595-603. [PubMed: 19656160]

6. Looker AC, Pfeiffer CM, Lacher DA, et al. Serum 25-hydroxyvitamin D status of the US population:1988-1994 compared with 2000-2004. Am J Clin Nutr. 2008; 88:1519-1527. [PubMed: 19064511]

7. Aasheim ET, Hofs $\varnothing$ D, Hjelmesaeth J, Birkeland KI, Bøhmer T. Vitamin status in morbidly obese patients: a cross-sectional study. Am J Clin Nutr. 2008; 87:362-369. [PubMed: 18258626]

8. Snijder MB, van Dam RM, Visser M, et al. Adiposity in relation to vitamin D status and parathyroid hormone levels: a population-based study in older men and women. J Clin Endocrinol Metab. 2005; 90:4119-4123. [PubMed: 15855256]

9. Reinehr T, de Sousa G, Alexy U, Kersting M, Andler W. Vitamin D status and parathyroid hormone in obese children before and after weight loss. Eur J Endocrinol. 2007; 157:225-232. [PubMed: 17656603]

10. Wortsman J, Matsuoka LY, Chen TC, Lu Z, Holick MF. Decreased bioavailability of vitamin D in obesity. Am J Clin Nutr. 2000; 72:690-693. [PubMed: 10966885]

11. Looker AC. Do body fat and exercise modulate vitamin D status? Nutr Rev. 2007; 65:S124-S126. [PubMed: 17867388]

12. Davis CD. Vitamin D and cancer: current dilemmas and future research needs. Am J Clin Nutr. 2008; 88:565S-569S. [PubMed: 18689403]

13. Gasteyger C, Suter M, Gaillard RC, Giusti V. Nutritional deficiencies after Roux-en-Y gastric bypass for morbid obesity often cannot be prevented by standard multivitamin supplementation. Am J Clin Nutr. 2008; 87:1128-1133. [PubMed: 18469230]

14. Bruno C, Fulford AD, Potts JR, et al. Serum markers of bone turnover are increased at six and 18 months after Roux-en-Y bariatric surgery: correlation with the reduction in leptin. J Clin Endocrinol Metab. 2010; 95:159-166. [PubMed: 19858320]

15. Rock CL, Flatt SW, Sherwood NE, et al. Effect of a free prepared meal and incentivized weight loss program on weight loss and weight loss maintenance in obese and overweight women: a randomized controlled trial. JAMA. 2010; 304:1803-1810. [PubMed: 20935338]

16. Montoye, HJ. Physical Activity and Health: An Epidemiologic Study of an Entire Community. Englewood Cliffs, NJ: Prentice-Hall; 1975. 
17. McArdle WD, Katch FI, Pechar GS, Jacobson L, Ruck S. Reliability and interrelationships between maximal oxygen intake, physical work capacity and step-test scores in college women. Med Sci Sports. 1972; 4:182-186. [PubMed: 4648576]

18. Carter GD, Carter R, Jones J, Berry J. How accurate are assays for 25-hydroxyvitamin D? Data from the international vitamin D external quality assessment scheme. Clin Chem. 2004; 50:21952197. [PubMed: 15375018]

19. Nesby-O'Dell S, Scanlon KS, Cogswell ME, et al. Hypovitaminosis D prevalence and determinants among African American and white women of reproductive age: third National Health and Nutrition Examination Survey, 1988-1994. Am J Clin Nutr. 2002; 76:187-192. [PubMed: 12081833]

20. Manson JE, Mayne ST, Clinton SK. Vitamin D and prevention of cancer-ready for prime time? N Engl J Med. 2011; 364:1385-1387. [PubMed: 21428761]

21. Jensen LB, Kollerup G, Quaade F, Sørensen OH. Bone minerals changes in obese women during a moderate weight loss with and without calcium supplementation. J Bone Miner Res. 2001; 16:141-147. [PubMed: 11149478]

22. Ortega RM, López-Sobaler AM, Aparicio A, et al. Vitamin D status modification by two slightly hypocaloric diets in young overweight/obese women. Int J Vitam Nutr Res. 2009; 79:71-78. [PubMed: 20108208]

23. Tzotzas T, Papadopoulou FG, Tziomalos K, et al. Rising serum 25-hydroxyvitamin D levels after weight loss in obese women correlate with improvement in insulin resistance. J Clin Endocrinol Metab. 2010; 95:4251-4257. [PubMed: 20534751]

24. Rickers H, Christiansen C, Balslev I, Rødbro P. Impairment of vitamin D metabolism and bone mineral content after intestinal bypass for obesity. A longitudinal study. Scand J Gastroenterol. 1984; 19:184-189. [PubMed: 6609420]

25. Newbury L, Dolan K, Hatzifotis M, Low N, Fielding G. Calcium and vitamin D depletion and elevated parathyroid hormone following biliopancreatic diversion. Obes Surg. 2003; 13:893-895. [PubMed: 14738677]

26. Slater GH, Ren CJ, Siegel N, et al. Serum fat-soluble vitamin deficiency and abnormal calcium metabolism after malabsorptive bariatric surgery. J Gastrointest Surg. 2004; 8:48-55. discussion 54. [PubMed: 14746835]

27. Roth HJ, Schmidt-Gayk H, Weber H, Niederau C. Accuracy and clinical implications of seven 25hydroxyvitamin D methods compared with liquid chromatography-tandem mass spectrometry as a reference. Ann Clin Biochem. 2008; 45:153-159. [PubMed: 18325178]

28. Heaney RP, Recker RR, Grote J, Horst RL, Armas LA. Vitamin D(3) is more potent than vitamin D(2) in humans. J Clin Endocrinol Metab. 2011; 96:E447-E452. [PubMed: 21177785]

29. Rock CL, Thornquist MD, Kristal AR, et al. Demographic, dietary and lifestyle factors differentially explain variability in serum carotenoids and fat-soluble vitamins: baseline results from the sentinel site of the Olestra Post-Marketing Surveillance Study. J Nutr. 1999; 129:855864. [PubMed: 10203561]

30. Wadden TA, Wing RR, Ryan DH, Neiberg R. Plenary Oral Abstract Presentations. Four-year weight loses in individuals with type 2 diabetes in the Look AHEAD Study. Obesity. 2009; 17:S76. 


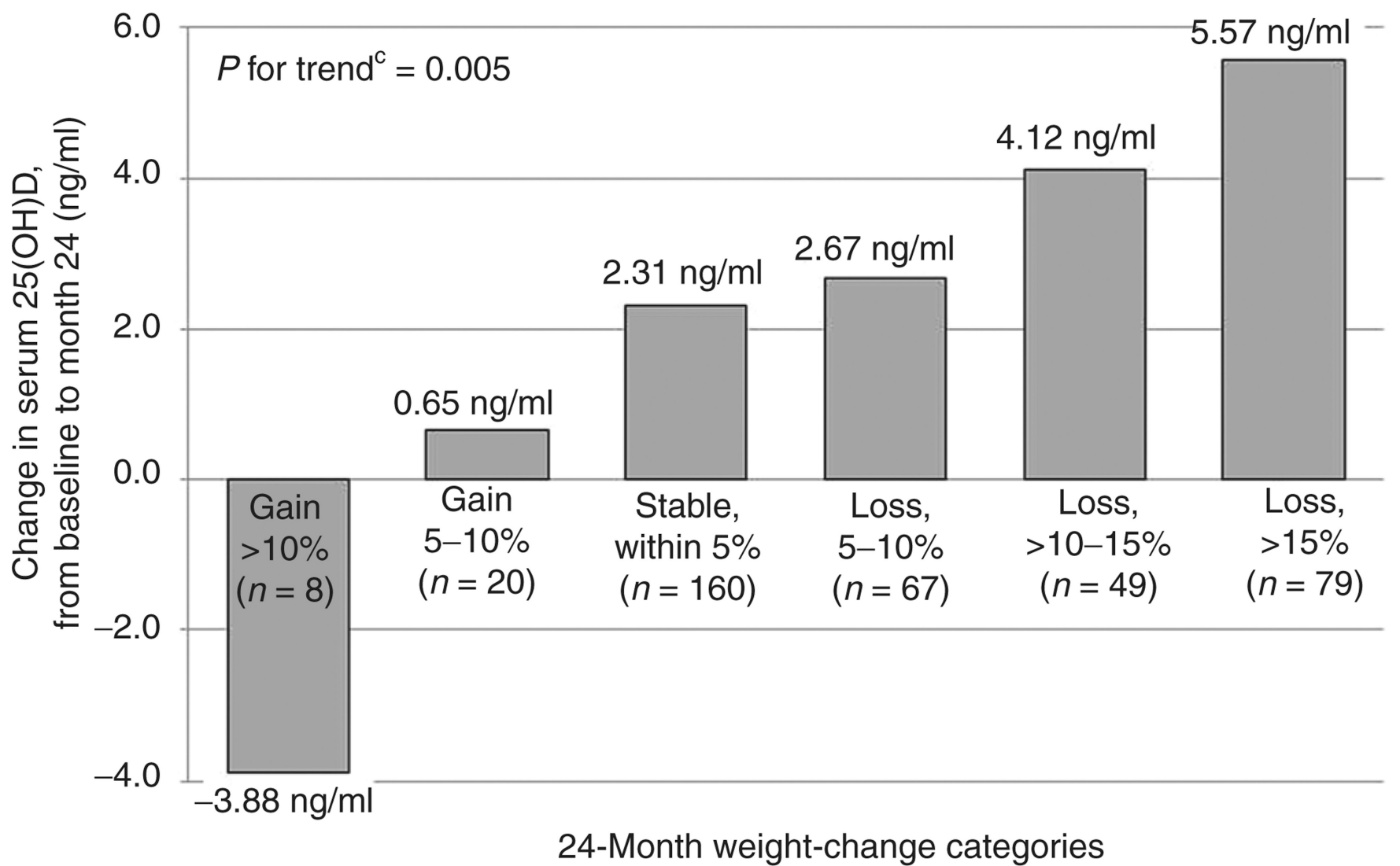

Figure 1.

Change in serum 25-hydroxyvitamin $\mathrm{D}(25(\mathrm{OH}) \mathrm{D})$ concentration $(\mathrm{ng} / \mathrm{ml})$ among participants in an analysis comparing weight loss and serum $25(\mathrm{OH}) \mathrm{D}$ concentration, by categories of weight change at 24 months ${ }^{\mathrm{a}, \mathrm{b}}$. ${ }^{\mathrm{a}} \mathrm{N}=383,{ }^{\mathrm{b}}$ Categories of weight change defined as percentage change from baseline weight observed at 24 months, ${ }^{c} P$ for trend from linear regression model testing linear trend across group means. 


\section{Table 1}

Baseline characteristics of participants in an analysis of weight loss and serum $25(\mathrm{OH}) \mathrm{D}$ concentration

\begin{tabular}{|c|c|c|c|c|}
\hline & \multicolumn{3}{|c|}{ 24-Month weight change category $a$} & \multirow[b]{2}{*}{$P^{c}$} \\
\hline & $\begin{array}{r}\text { Gain or } \\
\text { stable }^{b}\end{array}$ & $\begin{array}{r}\text { 5-10\% } \\
\text { Loss }\end{array}$ & $>10 \%$ Loss & \\
\hline Overall, $n(\%)$ & $188(49.1 \%)$ & $67(17.5 \%)$ & $128(33.4 \%)$ & - \\
\hline \multicolumn{5}{|l|}{ Recruitment site, $n(\%)$} \\
\hline Arizona & $51(52.6 \%)$ & $16(16.5 \%)$ & $30(30.9 \%)$ & 0.12 \\
\hline Minnesota & $52(50.5 \%)$ & $16(15.5 \%)$ & $35(34.0 \%)$ & \\
\hline Oregon & $32(35.6 \%)$ & $19(21.1 \%)$ & $39(43.3 \%)$ & \\
\hline California & $53(57.0 \%)$ & $16(17.2 \%)$ & $24(25.8 \%)$ & \\
\hline \multicolumn{5}{|l|}{ Age, $n(\%)$} \\
\hline$<40$ years & $63(57.8 \%)$ & $18(16.5 \%)$ & $28(25.7 \%)$ & 0.08 \\
\hline $40-69$ years & $125(45.6 \%)$ & $49(17.9 \%)$ & $100(36.5 \%)$ & \\
\hline \multicolumn{5}{|l|}{ Race/ethnicity, $n(\%)$} \\
\hline White, non-Hispanic & $139(47.4 \%)$ & $50(17.1 \%)$ & $104(35.5 \%)$ & 0.66 \\
\hline Black, non-Hispanic & $15(48.4 \%)$ & $6(19.4 \%)$ & $10(32.3 \%)$ & \\
\hline Hispanic & $23(54.8 \%)$ & $9(21.4 \%)$ & $10(23.8 \%)$ & \\
\hline Other & $11(64.7 \%)$ & $2(11.8 \%)$ & $4(23.5 \%)$ & \\
\hline \multicolumn{5}{|l|}{ Education, $n(\%)$} \\
\hline SHigh school graduate & $21(50.0 \%)$ & $7(16.7 \%)$ & $14(33.3 \%)$ & 0.84 \\
\hline Some college & $76(49.0 \%)$ & $24(15.5 \%)$ & $55(35.5 \%)$ & \\
\hline College graduate & $47(53.4 \%)$ & $17(19.3 \%)$ & $24(27.3 \%)$ & \\
\hline Graduate school & $44(44.9 \%)$ & $19(19.4 \%)$ & $35(35.7 \%)$ & \\
\hline \multicolumn{5}{|l|}{ BMI, $n(\%)$} \\
\hline $25-29.9 \mathrm{~kg} / \mathrm{m}^{2}$ & $27(50.9 \%)$ & $15(28.3 \%)$ & $11(20.8 \%)$ & 0.03 \\
\hline $230 \mathrm{~kg} / \mathrm{m} 2$ & $161(48.8 \%)$ & $52(15.8 \%)$ & $117(35.5 \%)$ & \\
\hline \multicolumn{5}{|c|}{ Vitamin D supplement use, $n(\%)$} \\
\hline None & $144(48.0 \%)$ & $56(18.7 \%)$ & $100(33.3 \%)$ & 0.73 \\
\hline 1-400 IU/day & $19(52.8 \%)$ & $3(8.3 \%)$ & $14(38.9 \%)$ & \\
\hline 401-999 IU/day & $14(53.9 \%)$ & $3(11.5 \%)$ & $9(34.6 \%)$ & \\
\hline$\geq 1,000 \mathrm{IU} /$ day & $6(42.9 \%)$ & $2(14.3 \%)$ & $6(42.9 \%)$ & \\
\hline
\end{tabular}

$N=383$.

25(OH)D, 25-hydroxyvitamin D.

${ }^{a}$ Categories of weight change defined as percentage change from baseline weight observed at 24 months.

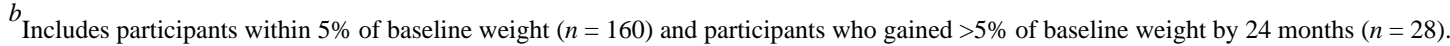

${ }^{c} P$ value from $\chi^{2}$ test. 
Table 2

Baseline concentrations of serum 25(OH)D (ng/ml) in an analysis of weight loss and serum 25(OH)D

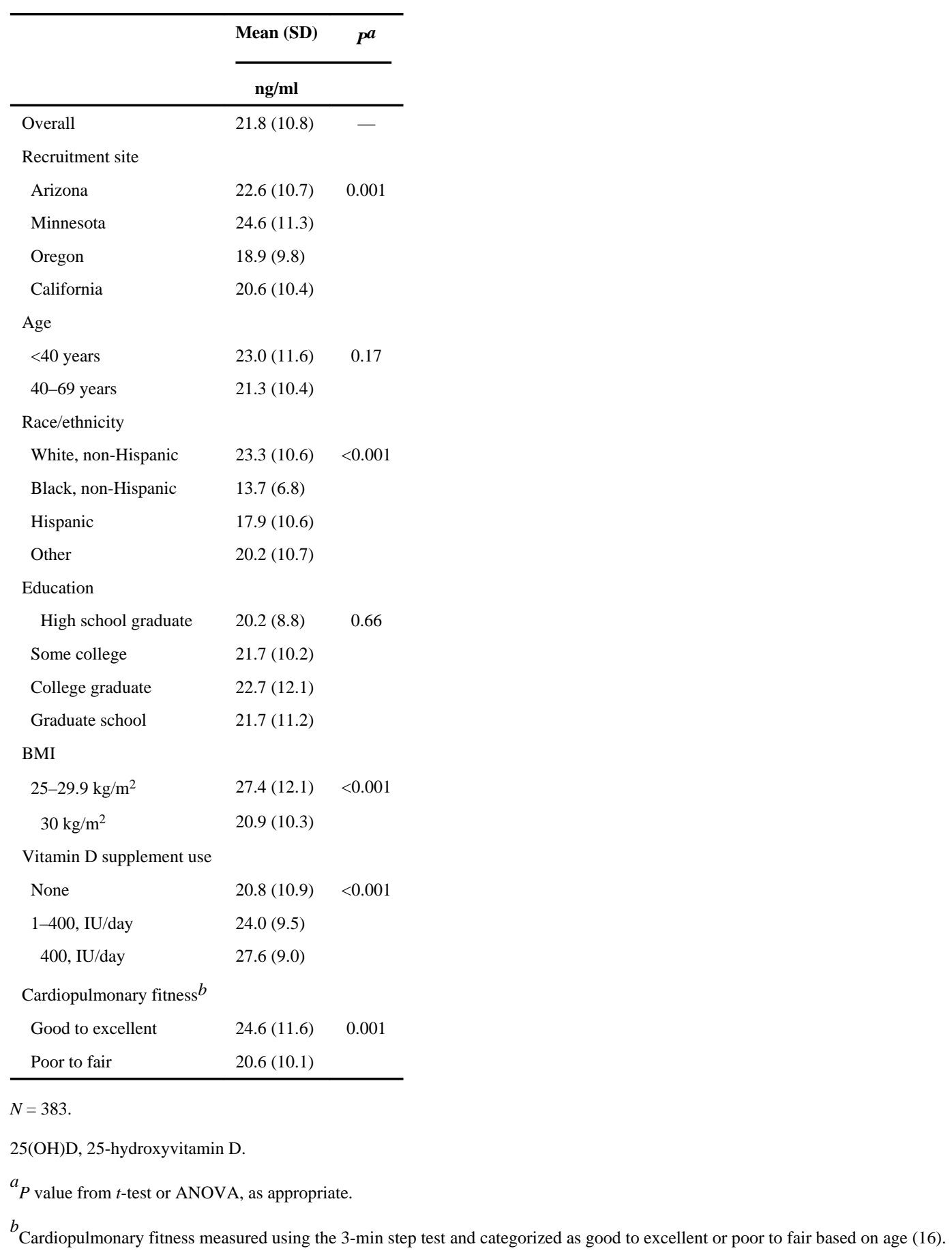


Table 3

Multivariate predictors of 24-month change in serum 25(OH)D among study participants of weight loss and serum $25(\mathrm{OH}) \mathrm{D}$

\begin{tabular}{|c|c|c|}
\hline & $\beta$-Coefficient (SE) ${ }^{a}$ & $P$ \\
\hline Intercept & $10.4(2.6)$ & $<0.001$ \\
\hline \multicolumn{3}{|c|}{ 24-Month weight change category $b$} \\
\hline Gain or stable $e^{c}$ & Referent & - \\
\hline $5-10 \%$ Loss & $0.7(1.2)$ & 0.57 \\
\hline$>10 \%$ Loss & $2.6(1.0)$ & 0.01 \\
\hline \multicolumn{3}{|l|}{ Baseline measures: } \\
\hline Serum 25(OH)D, ng/ml & $-0.4(0.04)$ & $<0.001$ \\
\hline \multicolumn{3}{|l|}{ Age } \\
\hline$<40$ years & Referent & - \\
\hline$\geq 40$ years & $1.7(1.0)$ & 0.09 \\
\hline \multicolumn{3}{|l|}{ Race/ethnicity } \\
\hline White, non-Hispanic & Referent & - \\
\hline Black, non-Hispanic & $-1.3(1.7)$ & 0.42 \\
\hline Hispanic & $-1.3(1.4)$ & 0.36 \\
\hline Other & $4.0(2.2)$ & 0.07 \\
\hline \multicolumn{3}{|l|}{ BMI } \\
\hline $25-29.9 \mathrm{~kg} / \mathrm{m}^{2}$ & Referent & - \\
\hline $230 \mathrm{~kg} / \mathrm{m}^{2}$ & $0.05(1.3)$ & 0.97 \\
\hline \multicolumn{3}{|l|}{ 24-Month measures: } \\
\hline \multicolumn{3}{|l|}{ Vitamin D supplement use } \\
\hline None & Referent & - \\
\hline $1-400$ IU/day & $2.2(1.2)$ & 0.06 \\
\hline$\geq 400 \mathrm{IU} /$ day & $6.5(1.0)$ & $<0.001$ \\
\hline Step test, heart rate $/ 30 \mathrm{~s}$ & $-0.03(0.04)$ & 0.42 \\
\hline
\end{tabular}

$N=383$. Model also adjusted for recruitment site and study arm.

25(OH)D, 25-hydroxyvitamin D.

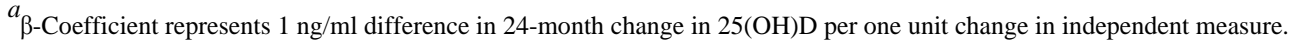

${ }^{b}$ Categories of weight change defined as percentage change from baseline weight observed at 24 months.

${ }^{c}$ Includes participants within $5 \%$ of baseline weight $(n=160)$ and participants who gained $>5 \%$ of baseline weight by 24 months $(n=28)$. 